\title{
CONVIVÊNCIA, AFETIVIDADES E EDUCAÇÃO PARA PAZ COMO ELEMENTOS DE PRÁTICAS EDUCATIVAS NÃO ESCOLARES EM CONTEXTOS DE VIOLÊNCIAS
}

\section{Coexistence, affection and education for peace as elements of non-school educational practices in contexts of violences}

Lucas Salgueiro Lopes Universidade do Estado do Rio de Janeiro (UERJ/FFP)

Arthur Vianna Ferreira Faculdade de Formação de Professores da (UERJ/FFP)

\section{Informações do artigo \\ Recebido em 22/12/2020 \\ Aceito em 23/04/2021}

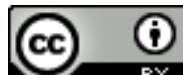

Esta obra está licenciada com uma Licença Creative Commons Atribuição 4.0 Internacional.

\section{Como ser citado (modelo ABNT)}

FERREIRA, Arthur Vianna; LOPES, Lucas Salgueiro. Convivência, afetividades e educação para paz como elementos de práticas educativas não escolares em contextos de violências. Cadernos do CEAS: Revista Crítica de Humanidades. Salvador/Recife, v. 46, n. 252, p. 74-102, jan./abr. 2021. DOI:

https://doi.org/10.25247/2447-861X.2021.n252.p74-102

\begin{abstract}
Resumo
O presente trabalho tem como objetivo investigar de que maneira as práticas educativas não escolares podem atuar como uma ferramenta potente nas regiões de vulnerabilidade social, de forma específica, em sua relação com o contexto de violências cotidianas vistas a partir de estudo realizado no Complexo do Salgueiro, em São Gonçalo-RJ. Assim, este artigo se utiliza de um referencial teórico do campo da Pedagogia Social de Xesús Jares (2002; 2007; 2008), da Psicologia, de Mahoney e Almeida (2015), da Sociologia, como com Johan Galtung $(1969 ; 2016)$ e da Filosofia, como com Byung-Chul Han (2017a; 2017b). Assim, tais autores auxiliam na delimitação e desenvolvimento de práticas de ensinoaprendizagem que denominamos Educação para Paz-Cidadania (LOPES, 2019). Para o diálogo com esses referenciais, utiliza-se a realidade expressa em duas pesquisas de campo anteriores: Ferreira e Lopes (2019) e Lopes (2019); nessas pesquisas, a metodologia utilizada foi a de observação de campo a partir da fenomenologia de Edmund Husserl. Dessa forma, busca-se ampliar a compreensão de conceitos como o de violências e suas possíveis articulações nas práticas socioeducativas dos indivíduos e nas relações de ensino-aprendizagem existentes nas regiões periféricas. Os resultados deste artigo apontam para a importância da atuação do terceiro setor nas práticas educativas das camadas empobrecidas, tal como para a possibilidade e importância de práticas de ensino-aprendizagem carregadas de valores ligados à convivência democrática, à afetividade, à paz positiva, à cidadania, entre outros elementos que possam gerar resultados favoráveis visando às demandas específicas dos educandos e da comunidade no seu entorno.
\end{abstract}

Palavras-Chave: Sociologia da Violência. Convivência. Afetividades. Educação para Paz-Cidadania.

\section{Abstract}

The present article investigates how non-school educational practices act as a potent tool in regions of social vulnerability, specifically, in their relationship with the context of violences from a study at the Complexo do Salgueiro, in São Gonçalo-RJ. This article uses a theoretical framework from the field of Social Pedagogy of Xesus Jares $(2002 ; 2007 ; 2008)$, from Psychology, with Mahoney and Almeida (2015), Sociology, as with the Typology of Violence used by Johan Galtung $(1969 ; 2016)$ and Philosophy, as with the Positivity's violence by Byung-Chul Han (2017a, 2017b.). Thus, such authors assist at the delimitation and development of teachinglearning practices that we call Education for Peace-Citizenship (LOPES, 2019). For the dialogue with these references, we will use the reality expressed in two previous field: Ferreira e Lopes (2019) and Lopes (2019); in these researches, the methodology used was that of field observation based on the phenomenology of the Edmund Husserl. Thus, it seeks to understanding of concepts such as violence and its possible articulations in the socio-educational practices of individuals and in the teachinglearning relationships existing in peripheral regions. The results of this article point to the importance of the performance of the third sector in the educational practices for the poor's people, as well as to the possibility - and great importance - of teaching-learning practices loaded with values linked to democratic coexistence, affectivity, peace, positive, citizenship, among other elements that can generate favorable results aimed at the specific demands of students and their community.

Keywords: Social Pedagogy. Sociology of Violence. Coexistence. Affection. Education for Peace-Citizenship. 


\section{Introdução}

O presente artigo parte de duas questões centrais: como as violências e o contexto social presentes no Complexo do Salgueiro atualmente influenciam na vida cotidiana e educacional dos moradores da região? Como a Educação pode servir como instrumento para combater essas violências em um contexto tão marcado pela desigualdade social? Dessa maneira, tem-se como objetivo apontar as relações entre afetividade e convivência no desenvolvimento dos processos de ensino-aprendizagem nas práticas socioeducativas dessa localidade, tal como a possibilidade da implantação da Educação para Paz nesses ambientes.

Para os conceitos de convivência e Educação para Paz, o principal referencial foi o educador Xesús Jares (2002; 2007; 2008). Para afetividade, partindo do pensamento de Henri Wallon, foi utilizado o trabalho de Abigail Mahoney e Laurinda Almeida (2015). A partir desses referenciais, visa-se vislumbrar as potencialidades da Educação na luta contra as violências - em suas mais diversas formas - e a desigualdade social como um todo, resultando no modelo que denominamos como Educação para Paz-Cidadania em Lopes (2019). As violências, nesse sentido, serão abordadas a partir de suas formas direta, estrutural e cultural, tal como proposto por Johan Galtung (1969; 2016), além dos significados - e dos desdobramentos - contidos na violência da positividade, conforme visto em Byung-Chul Han (2017a; 2017b).

Para a melhor compreensão desses conceitos, utilizou-se do contexto das práticas socioeducativas no Complexo do Salgueiro, ${ }^{1}$ referendadas por publicações referentes a duas

\footnotetext{
${ }^{1}$ Denominamos aqui como "Complexo do Salgueiro" as favelas de alguns bairros do $1^{\circ}$ distrito de São GonçaloRJ, tais como: Salgueiro, Palmeira, Recanto das Acácias, Itaúna, Itaoca e Fazenda dos Mineiros. Essa interligação se dá, inicialmente, sobretudo, por essas regiões possuírem domínio de uma mesma facção criminosa, o Comando Vermelho. Por outro lado, ainda que haja regiões com razoável nível de saneamento básico e uma atuação - ainda que mínima - do poder público em locais pontuais desses bairros (como, por exemplo, o denominado "Rodo de Itaúna", região central do Complexo que abriga alguns estabelecimentos comerciais e tem suas ruas e habitações mais distantes das características comuns das favelas ao entorno), a maior parte dessa região segue um padrão sociocultural muito similar, caracterizado pela forte presença das violências, problemas de urbanização, moradias precárias, falta de serviços públicos básicos, alto índice de desemprego, etc. Por fim, cabe acrescentar, para reiterar ainda mais tal posição de uso dessa denominação, que esse é o termo usado pela maior parte das autoridades públicas para denominar a região, tal como, é aceito e utilizado com frequência pelos moradores desses locais. Dessa forma, definimos como "Complexo do Salgueiro" o "cinturão" de favelas que circundam o bairro homônimo do Salgueiro, caracterizado como região empobrecida e marginalizada, e possuindo entre si demandas e condições similares, tal como um considerável sentimento de grupo entre seus moradores.
} 
pesquisas de campo realizadas pelos autores deste trabalho nos últimos anos: a primeira, ${ }^{2}$ em oficinas do projeto Luxo de Vida, em 2017, e a segunda, ${ }^{3}$ a partir de visitas ao prévestibular comunitário do projeto Mulheres do Salgueiro em 2018.

A ONG Luxo de Vida foi fundada em 2014 no bairro de Itaúna. O projeto se iniciou com a psicóloga Girlene Falcão, moradora do bairro, que possuía a intenção de reformar uma área pública do local repleta de lixo e animais como cobras, ratos e porcos. A partir desse objetivo, nasceu a ação de criar uma oficina de reciclagem com as crianças do bairro. Com mais de seis anos de existência, o Luxo de Vida tem como foco principal a sustentabilidade e a Educação Ambiental, mas também atende crianças e adolescentes com diversas oficinas pedagógicas, além de ações para moradores da região de todas as idades. Em pesquisa realizada durante o ano de 2017, a partir de visitas à sede do projeto e entrevistas semiestruturadas, a ONG oferecia oficinas voltadas a segmentos educacionais, esportivos, artísticos e lúdicos (FERREIRA; LOPES, 2019, p. 8-9).

O projeto Mulheres do Salgueiro funciona desde 2006. Suas primeiras ações se dão há cerca de 18 anos, com a criação de uma creche que visava auxiliar as mães da região, em sua maioria, trabalhadoras do Lixão de Itaoca. Os trabalhos acabam se expandindo a partir da oportunidade que nasce com o interesse de uma ONG Alemã em financiar um projeto no Brasil4; com essa ajuda, foi comprada a atual sede. Sobre o trabalho realizado na ONG:

Um grupo de mulheres que terminou o curso [curso livre de corte e costura industrial] fundou uma cooperativa. Haviam descoberto pela internet uma outra cooperativa que cultivava tilápias. Foi firmada uma cooperação, nossas costureiras compravam o couro dos peixes, que curtiam, tingiam e transformavam em jaquetas, bolsas e capas de almofadas. Vendiam seus produtos em mercados regionais da economia solidária. (TAUFER, 2018, p. 269).

\footnotetext{
${ }^{2}$ FERREIRA, A. V.; LOPES, L. S. O uso das afetividades em Wallon e as práticas socioeducativas de um projeto social em São Gonçalo - RJ. Revista Debates em Educação, Maceió, vol. 11, n. 25, set./dez., 2019, p. 1-21.

3 LOPES, L. S. EDUCAÇÃO PARA PAZ-CIDADANIA: as (possíveis) práticas socioeducativas num pré-vestibular comunitário no Complexo do Salgueiro em São Gonçalo-RJ. In: FERREIRA, A. V.; LOPES, L. S.; DIAS, T. S. (Org.). Fora da Sala de Aula: Formação Docente e Pesquisas sobre Pobreza e Educação. $1^{a}$ ed. Rio de Janeiro: Autografia, 2019, p. 54-81.

4 Essa relação do Mulheres do Salgueiro com a ONG da Alemanha foi contada na autobiografia do exguerrilheiro e ativista social alemão Lutz Taufer (2018). Por aqui, atuando como cooperante da ONG Centro de Assessoria ao Movimento Popular (CAMPO), desenvolveu diversos projetos em favelas de São Gonçalo. O CAMPO tornou-se, desde os anos 1990, uma organização parceira da ONG alemã Serviço pela Paz Mundial (Weltfriedensdienst), onde atualmente Lutz Taufer é integrante da diretoria.
} 
A pesquisa no projeto Mulheres do Salgueiro foi realizada durante 2018, por meio de trabalho de campo e entrevistas semiestruturadas, focando principalmente no pré-vestibular comunitário que funciona no local. Segundo Janete Nazareth, coordenadora do projeto, a atuação da ONG ocorre a partir de três alicerces: empoderamento e emancipação das mulheres, combate à violência e profissionalização. A profissionalização é feita com as mulheres da comunidade por meio de atividades de costura e comércio dos produtos, gerando renda de forma cooperativista. O conceito de Economia Solidária fundamenta o trabalho de distribuição de renda da ONG, funcionando como uma forma de alternativa ao sistema capitalista. Para o financiamento das atividades do Mulheres do Salgueiro, é destacada também a participação do Projeto em editais de apoios financeiros de empresas maiores.

\section{Metodologia}

Embora esse artigo venha trazendo fundamentações teóricas para o trabalho educativo não escolar em contextos de vulnerabilidade social, ele também se propõe a recuperar as práticas socioeducativas realizadas no Complexo do Salgueiro presentes em duas publicações anteriores dos autores do presente trabalho: Ferreira e Lopes (2019) e Lopes (2019). Nessas duas pesquisas, a metodologia utilizada foi a de observação de campo a partir da fenomenologia de Edmund Husserl (DEPRAZ, 2011).

Para Natalie Depraz (2011, p. 30-33), o método fenomenológico husserliano se faz com base na descrição. $\mathrm{O}$ ato de descrever pode ser definido como uma forma de "dizer o que se vê", visando, dessa forma, à apresentação mais completa possível do fenômeno em questão. Cabe destacar, no entanto, que, ao buscar uma forma de descrição mais completa possível, entendemos essa "completude" da situação como inalcançável, por um lado, mas permanente buscável por outro. Assim, os diários de campo são divididos, com base na estrutura fenomenológica de Husserl, em: noema, noese e variação eidética. O noema é a parte mais objetiva do relato acerca do fenômeno, onde se apresenta a situação da maneira mais imparcial possível, de forma descritiva. O noese, diferente disso, seria mais subjetivo, sendo uma descrição em que o sujeito pode expor suas percepções, lembranças e sentimentos sobre o fenômeno, ou seja, como ele experimentou e reagiu ao objeto investigado. A variação eidética (ou redução eidética), finalmente, é a maneira de relatar o 
fenômeno com base nas (supostas) visões e sentimentos dos outros agentes que fizeram parte da ação investigada; é, assim, um meio de o sujeito que relata experienciar a ação de uma maneira mais "empática", considerando a forma como o fenômeno agiu sobre o outro (LOPES; FERREIRA, 2019).

No material presente neste artigo, acerca das consequências das Unidades de Polícia Pacificadora (UPP) e da Intervenção Federal de 2018 no Rio de Janeiro, foram compilados os dados encontrados a partir de consultas às veiculações da mídia sobre os temas, pesquisa à bibliografia acadêmica produzida por outros autores, e levantamentos a partir de pesquisa no Instituto de Segurança Pública (ISP).

\section{O contexto da produção de violências: São Gonçalo e o Complexo do Salgueiro}

Segundo o censo do IBGE de 2010, São Gonçalo possui 999.728 habitantes, tendo uma estimativa para 2020 que chega próxima ao número de um milhão e cem mil pessoas. Tendo sido um município majoritariamente agrícola até o início do século $X X$, o auge da prosperidade e do desenvolvimento econômico de São Gonçalo ocorreu em meados do século XX, ligado à intensa produção industrial que the rendeu o apelido de "Manchester Fluminense". Nas décadas subsequentes, a população gonçalense foi se multiplicando, e os tempos áureos de "Manchester" passaram a ficar cada vez mais longe. Com uma menor oferta de empregos, segue, atualmente, a era de São Gonçalo como "cidade-dormitório", passando por um abandono cada vez mais comum - por tarde do poder público - às regiões mais empobrecidas, como apresentado por Moraes (2014).

Nos índices de educação, São Gonçalo tem taxa de escolarização (de 6 a 14 anos de idade) em 96,7\%, posição 72 de 92 municípios do Estado; a avaliação do Índice de Desenvolvimento da Educação Básica (IDEB) de 2019 coloca São Gonçalo com o quarto pior desempenho nos anos iniciais do ensino fundamental do estado (nota 4,6 ) e com o oitavo pior na avaliação dos anos finais do ensino fundamental (nota 3,7 ).

Escrever este artigo no contexto atual parte de dois importantes marcos de tentativas de políticas públicas para "combater a violência" no Rio de Janeiro: as Unidades de Polícia Pacificadora (UPP) e a Intervenção Federal de 2018. As UPPs tiveram início há mais de uma década, em 2008, em projeto do governo do estado do Rio de Janeiro que visava à 
implementação de unidades de polícia em locais que estivessem sob o controle de grupos criminosos. Dessa maneira, as UPPs visavam à retomada desses territórios ao poder do Estado, tal como à diminuição da criminalidade violenta, conforme presente no decreto No 45.186, de 17 de março de $2015 \cdot{ }^{5}$ As Unidades foram implementadas em mais de 30 favelas do estado, em sua maioria da Capital. Essa visão institucional, no entanto, que vê a "ação pacificadora" como um meio para restaurar o controle estatal das favelas controladas pelo tráfico, ainda é muito simplista, ou melhor, obscura quanto aos seus reais significados. Como Oliveira (2014) elucida bem, "pacificar", nesse sentido, carrega uma forte analogia colonial, onde aquele que deve ser potencialmente pacificado é o que não se submete voluntariamente às autoridades administrativas da época. Assim:

A "comunidade pacificada", na visão dos planejadores e nas representações da mídia, não é só aquela onde se desenrolou uma ação militar para desalojar o controle do crime organizado, mas aquela em que os moradores e as condições de vida teriam passado por uma modificação completa, fruto de uma ação supostamente de natureza civilizatória [...] Os executores da política de segurança e os policiais em geral imaginam os morros usualmente como "o espaço do inimigo". Os habitantes das favelas, à diferença dos demais cidadãos, são vistos como colaboradores em relação ao seu próprio mal, portadores de uma permissividade ou insuficiência moral que não os distingue suficientemente do crime organizado. (OLIVEIRA, 2014, p. 138).

Não entraremos, aqui, no debate acerca da efetividade e dos resultados dessa implementação nas favelas do Rio de Janeiro, mas, voltado ao que nos interessa, aos efeitos que as Unidades de Polícia Pacificadora causaram em São Gonçalo. Mesmo sem nenhuma Unidade instalada em favelas do munícipio, São Gonçalo experimentou um forte efeito das UPPs: a migração de bandidos oriundos das favelas ocupadas pela polícia na Capital. Dessa forma, nota-se um fortalecimento do domínio de grupos criminosos, em particular ligados à facção Comando Vermelho, nas comunidades de São Gonçalo. Nesse contexto, o Complexo do Salgueiro foi um dos locais mais afetados, com cada vez maior extensão de zona controlada por esse "poder paralelo". Esse incremento contribui para o reconhecimento da área pela segurança do estado como maior zona de influência do Comando Vermelho no Rio

\footnotetext{
5 Disponível em: http://www.silep.planejamento.rj.gov.br/decreto_45_186_-_17032015_-_re.htm. Acesso em 18 de dezembro de 2019 .
} 
de Janeiro. ${ }^{6}$ Segundo levantamento realizado por Ferreira e Silva (2018), dos 30 bairros do primeiro distrito de São Gonçalo - no qual o Complexo do Salgueiro está incluso - foram identificados 24 aglomerados subnormais (favelas); dessas 24 favelas, 23 eram controladas pelo Comando Vermelho no momento da pesquisa.

Tais apontamentos, que levam a crer na migração e na expansão da criminalidade em São Gonçalo no pós-UPP, não são uma novidade exposta aqui. Menos de 2 anos após a implantação da primeira UPP, na Favela Santa Marta, no bairro de Botafogo, tal movimento já era investigado pela polícia. Naquela ocasião, foi identificada a migração de bandidos do Comando Vermelho da Zona Norte do Rio (da Favela do Jacarezinho) para o Morro do Rato Molhado, na Região Oceânica de Niterói; a favela, localizada no bairro de classe média alta Itaipu, tinha histórico pacato até então.7 Em 2012, José Mariano Beltrame, Secretário de Segurança Pública do Rio de Janeiro, reconheceu a existência dessa migração da criminalidade para São Gonçalo e Niterói, apesar de explicitar que a polícia não tinha uma noção exata das suas proporções: "Não existe uma informação técnica de que haja efetivamente a migração. Claro que ela há, mas isso não é um dado mensurável, se é um, se são cem ou se são mil". ${ }^{8}$ Naquele momento, o secretário prestava contas sobre o grande avanço da violência na Região Metropolitana do Rio de Janeiro; no mês de fevereiro de 2012, em comparação ao mesmo mês do ano anterior, a Região experimentou um aumento de $500 \%$ no roubo de residências, $80 \%$ no roubo de veículos e lojas e $12 \%$ no roubo de pedestres. ${ }^{9} \mathrm{O}$ artigo de Fernandes Júnior (2016) elucida bem esse movimento de migração da criminalidade a partir da territorialização das UPPs. Segundo o autor:

O processo de deslocamento da criminalidade segue um desdobramento lógico, onde os criminosos migram das áreas territorializadas pela implementação das UPPs para outras regiões mais próximas comandadas pela mesma facção criminosa e até mesmo ultrapassam este nível de abrangência numa escala de metropolização da criminalidade, numa

6 Como visto no depoimento do delegado Marcus Amin no início de 2017. Disponível em: http://odia.ig.com.br/rio-de-janeiro/2017-03-31/traficante-desafia-policia-a-entrar-em-comunidade-de-saogoncalo.html. Acessado em 18 de dezembro de 2019.

7 Disponível em: https://sao-paulo.estadao.com.br/noticias/geral,rio-investiga-migracao-do-trafico-paraoutras-cidades-imp-,639208. Acesso em 18 de dezembro de 2019.

8 Disponível em: http://g1.globo.com/bom-dia-brasil/noticia/2012/04/bandidos-migram-de-comunidadespacificadas-e-assalto-violento-explode-em-regiao-metropolitana-do-rio.html. Acesso em 19 de dezembro de 2019.

9 Idem. 
dinâmica de migração e de expansão territorial. (FERNANDES JÚNIOR, 2016 , p. 21).

Já a Intervenção Federal no estado do Rio de Janeiro ocorreu uma década depois, em 2018, após decreto assinado pelo então presidente Michel Temer. O decreto 9.288 de 16 de fevereiro de 2018 tinha por objetivo "pôr termo ao grave comprometimento da ordem pública" no estado. Para isso, foi criado o cargo de interventor, de natureza militar, que comandaria toda a segurança pública do Rio, sem estar sujeito às normas estaduais que pudessem conflitar com as medidas da Intervenção. Durante o período, o Salgueiro foi um dos principais alvos diretos da Intervenção, convivendo com violentos confrontos durante operações militares.

Após quase um ano com os militares no comando da segurança do Rio de Janeiro, os dados do Instituto de Segurança Pública (ISP) mostram alguns dos resultados da Intervenção Federal sobre a incidência criminal no estado: o número de mortes por intervenção de agentes do estado cresceu 35,9\% em comparação a 2017 (1.532 mortes contra 1.127); o número de lesões corporais seguidas de morte cresceu 43,6\% (56 casos em 2018 contra 39 em 2017); cresceu também o número total de roubos, 0,5\% a mais em relação ao ano anterior (231.624 contra 230.437); diminuiu em 3\% o número de policiais mortos em serviço (foram 28 em 2018) e em $7 \%$ o número de homicídios dolosos ( 4.936 contra 5.346 no ano anterior). 0 número de apreensão de drogas (tráfico de drogas), um dos principais objetivos da suposta "luta contra a criminalidade" no estado, diminuiu durante a Intervenção: foram 1,1\% apreensões a menos que em 2017.

No Salgueiro em específico, inúmeros foram os relatos de crimes militares e abusos policiais durante a Intervenção. Na pesquisa realizada durante esse período, no pré-vestibular do Mulheres do Salgueiro (LOPES, 2019, p. 92-93), os relatos de violações de direitos por parte dos militares foram muito presentes nos comentários das alunas da instituição. Diversas vezes foram relatadas invasões de casas e revistas abusivas; foi relatada a morte (não identificada) de um entregador de gás durante um baile funk, além de constantes relatos da continuidade de ações das facções criminosas que já atuavam na região. Os relatos das alunas sobre comportamentos abusivos dos militares durante a Intervenção Federal não são os únicos. O "Circuito Favelas por Direitos", iniciativa de órgãos públicos e civis, percorreu mais de 30 favelas - incluindo o Salgueiro - durante a Intervenção Federal e, após quase oito 
meses, recolheu mais de 500 depoimentos de moradores que denunciaram violações de direitos civis por parte da atuação dos militares. ${ }^{10}$

O que se pode interpretar, a partir dessas duas tentativas (da "pacificação" a "intervenção") do Estado na última década, é um movimento de crescente militarização das políticas de lei e de ordem em todo país, onde, como lembra Costa (2019), as margens, como as periferias e favelas das grandes cidades atuais, se "fronteirizam" cada vez mais. Isso porque são as favelas que agora também sofrem com intervenções do mesmo cunho que as fronteiras passavam: sendo considerados locais de "pouco controle", de "perigo iminente", onde é necessária a ação num caráter de tutela, proteção e repressão. Como destaca o autor:

É provável que estejamos diante de um processo, em curso, em que novas práticas, experiências e tecnologias militares de controle estão sendo aplicadas em cidades a partir das experiências das Forças Armadas realizadas nas operações fronteiriças e no exterior. (COSTA, 2019, p. 19).

Dessa maneira, para Costa, marcos como as UPPs e a Intervenção Federal no Rio de Janeiro representam a grande proliferação das "fronteiras onipresentes" ${ }^{11}$ para dentro do território nacional. E quais os efeitos sociais disso? Oliveira (2014, p. 139-142) aponta para uma série de práticas do Estado (e seus agentes) que reforçam, cada vez mais, as diferenças - tal como as fronteiras entre moradores de favelas e os demais cidadãos -; essas, podem ser resumidas em quatro elementos: a vigilância permanente e ostensiva; a instauração de um medo doentio e representação das favelas como área de perigo extremo - e não só dos criminosos; a transformação das favelas em guetos e a divisão da cidade em locais com diferença radical de acesso a cidadania; a naturalização da morte e do aprisionamento. Infere-se, assim, a partir da atuação tutelar militarizada,

10 Para acesso ao relatório completo e todos os relatos ver: http://sistemas.rj.def.br/publico/sarova.ashx/Portal/sarova/imagemdpge/public/arquivos/Relato\%CC\%81rio_Final_Circuito_de_Favelas_por_Direitos_vg.pdf. Acessado em 19 de dezembro de 2019.

11 "De acordo com Graham (2016, p. 29), está em curso uma transformação na natureza dos Estados-nação, que cada vez mais afastados da ideia de uma comunidade de cidadãos que habita seu interior, policiam suas relações com o 'exterior' e se tornam, por sua vez, sistemas internacionais de controle dos fluxos de pessoas e circulações consideradas 'de risco' e perigosas, atuando para aquelas que devem ser protegidas. De acordo com esse autor, essas 'fronteiras onipresentes' ocorrem tanto para dentro dos territórios nacionais quanto para fora, tornando indistintas as fronteiras internacionais e as fronteiras urbanas e locais (Idem). Para Graham, o 'novo urbanismo militar' multiplica os pontos de controle e ações contínuas das chamadas 'guerras securocráticas', que não têm data para acabar e não são mais territorializadas (contra as drogas, o crime, o terror, a imigração ilegal e ameaças biológicas)" (COSTA, 2019, p. 35). 
a possibilidade de colocar uma parcela da população (que mesmo assim em parte os legitima) em um estado perene de suspeição legal ou criminal (e moral, inclusive), especialmente sob a retórica da segurança pública e nacional. Outro efeito dessas políticas é a hierarquização entre as pessoas que devem ser protegidas e outras que são vistas como ameaças, como grupos potencialmente perigosos. (COSTA, 2019, p. 38).

\section{Um olhar sobre as violências e suas manifestações no contexto fluminense}

Passadas as devidas contextualizações acerca do recorte espacial trabalhado nesse artigo, cabe, agora, lançar um olhar teórico sobre as ocorrências listadas. Desse modo, podemos entender melhor como essas especificidades dialogam com um dos termos centrais dessa pesquisa: as violências (assim mesmo, no plural). Numa primeira impressão, poderia parecer que a violência se demonstra nesse contexto através do alto número de mortes, confrontos policiais e ações criminosas; tal afirmação não estaria incorreta, porém, não daria conta de toda profundidade da iminente violência encontrada no Salgueiro e nas demais regiões marginalizadas como um todo.

O termo violências, sobretudo quando utilizado no âmbito acadêmico, é bastante complexo e dificilmente chegaria a um consenso quanto a seus tipos e suas classificações. É também de se destacar que poucos comportamentos, vistos de maneira isolada, poderiam ser considerados violentos por si. Assim, ao menos três aspectos devem ser levados em consideração para circundar adequadamente essa definição: seu momento histórico (o que é considerado violento no Século XXI pode ser uma prática normal da Era Medieval, por exemplo); a cultura (em seu sentido mais amplo, onde, por exemplo, uma prática comum e amplamente aceita para civilizações orientais pode ser vista como violenta para a cultura ocidental); a relação e o contexto em que o comportamento violento em questão ocorreu. Infere-se, então, que as violências não podem ser vistas de maneira a-histórica, atemporal e independente. (PESCAROLO, 2017, p. 130).

Em relação a uma tipologia das violências, entre muitos modelos propostos, consideramos o mais adequado para essa pesquisa utilizar o proposto pelo sociólogo norueguês Johan Galtung, em que a violência se dividiria em três tipos: direta, estrutural e cultural. Xésus Jares - que utiliza ateoria da violência de Galtung em seu modelo pedagógico - resume bem essas duas formas: 
Estabelece-se uma diferença fundamental entre violência direta e violência estrutural, entendendo-se a primeira como agressão física direta, a violência "tradicional", a mais facilmente reconhecível; e a segunda, indireta e mais invisível, presente em determinadas estruturas sociais, sinônimo da injustiça social. (JARES, 2007, p. 32).

A definição de violência estrutural de Galtung parte de artigo de 1969, contribuindo fortemente com as pesquisas dos estudos sobre a paz. Como destaca o autor: "A violência é construída na estrutura e aparece como poder desigual e, consequentemente, como chances de vida desiguais." (GALTUNG, 1969, p. 171, tradução nossa). Posteriormente, Galtung adicionou a esfera da violência cultural em seus trabalhos:

Por violência cultural nos referimos a aqueles aspectos da cultura, da esfera simbólica da nossa existência - materializado na religião e na ideologia, na linguagem e na arte, na ciência empírica e na ciência formal (a lógica, as matemáticas) - que podem ser utilizadas para justificar ou legitimar a violência direta ou a violência estrutural (...) A violência cultural faz com que a violência direta e a estrutural apareçam e se percebam, como carregadas de razão, - ou, ao menos, que sinta-se que não estão equivocadas. (GALTUNG, 2016, p. 149, tradução nossa).

Nesse sentido, como se coloca o contexto do Complexo do Salgueiro em relação à violência? Ao falarmos de todo o processo de operações militares durante a Intervenção Federal em 2018, fica clara a presença massiva da violência direta no cotidiano dos moradores. Durante as aulas relatadas em Lopes (2019), nota-se que as alunas do prévestibular comunitário do Salgueiro comentavam, em grande escala, sobre os abusos de militares durante as operações da Intervenção. Mas a situação vai além: a violência estrutural e a cultural se fazem tão presentes quanto. Como visto numa aula de Redação do prévestibular que retrata bem isso:

Em outro dia, antes do início de mais uma aula de Redação, a Professora pediu que as alunas a ajudem realizando entrevistas para sua monografia (...) O tema das perguntas era sobre "Política do bairro e oportunidades de emprego". Todas as alunas que são solicitadas participam da entrevista. Algumas falas recorrentes apontam para o problema com a violência. Destaque também para algumas que remetem a criatividade dos moradores e um empreendedorismo que deveria ser mais incentivado. Aluna A diz: "Quando procuro emprego em locais como Niterói, Icaraí... já olham de cara feia quando veem onde moro, ainda mais sendo negra (...) Aí nunca mais me chamaram". A Professora pergunta: "Tem jeito para esse preconceito?". "Acho que não", responde a Aluna. (LOPES, 2019, p. 69).

As perguntas voltadas à percepção das alunas sobre o próprio bairro e o lugar onde vivem causam importantes reflexões. A aluna destacada cita a questão do racismo e do 
preconceito por origem social que é recebido quando busca emprego em lojas de alto padrão financeiro; ao buscar emprego em bairros de classe alta, essa se sente discriminada e sem chances de conseguir a vaga, por dizer onde mora ou por ser negra. Por esse exemplo, notamos a violência estrutural que ainda há nas formas de discriminar a cor e classe social; a violência cultural se dá pelas formas que estereótipos desse tipo seguem "naturais" em nossa sociedade: do negro ou pobre visto como marginal, não confiável, aquele que não se encaixa nos padrões desejados para trabalhar em certos locais. Assim, vemos a forte difusão da violência estrutural e cultural em forma de ideias racistas e preconceituosas.

A partir desses exemplos, podemos classificar a violência direta como uma forma de violência física, onde se age contra o corpo e/ou a vida do outro de maneira objetiva; do mesmo modo, podemos inferir que as violências estruturais e culturais estão no âmbito da violência simbólica, ${ }^{12}$ conceito elaborado por Pierre Bourdieu, e que apresenta os atos violentos em seus aspectos mais invisibilizados e implícitos, tornando mais difícil sua eliminação, visto que, muitas vezes, nem é considerada como uma forma de violência.

Para além dos tipos apresentados, que bem dão conta do recorte espacial e do contexto social estudado, uma forma de violência sistêmica, mais ligada ao tempo histórico atual e a um contexto de mundo globalizado, é de importante destaque a violência da positividade. Elaborada pelo filósofo sul-coreano Byung-Chul Han (2017b), a violência da positividade seria a manifestação de violência dos tempos atuais, de uma sociedade do cansaço, que orienta a vida, cada vez mais, para uma superprodução, superdesempenho, supercomunicação e superinformação que acabam por favorecer o desgaste das relações sociais e o cansaço psíquico que as mesmas produzem entre os seus sujeitos.

A partir desse ponto, o autor questiona as teorias da violência de Galtung e Bourdieu - tal como de outros autores como Michel Foucault e Slavoj Žižek - considerando-as generalistas ou confusas ao não diferenciar violência de poder. Da mesma maneira, o sulcoreano nega a ocorrência, nos dias atuais, do que ele chama de violência da negatividade, que seria a versão desses outros autores, que Ihe são antagonistas: uma violência que

\footnotetext{
12 "As violências simbólicas são aquelas invisibilizadas por aqueles que as cometem e as sofrem por não considerarem tais ações violentas mediante uma série de processos de naturalização desses comportamentos (...) Para que uma violência possa ser percebida como tal, é necessário retirar o véu de naturalização que a reveste" (PESCAROLO, 2017, p. 134).
} 
restringe, que domina, que limita as capacidades potenciais e a liberdade do outro, sendo imposta de cima para baixo, numa reação verticalizada de dominação. Para Han (2017b), a violência que domina nossos tempos não mais limita, mas, ao contrário, dá uma liberdade extrema para as pessoas; do mesmo modo, não é mais uma violência imposta ou exercida das classes mais altas sobre as mais baixas: as pessoas são autoexploradas, nas classes altas ou baixas. É nesse sentido que a violência da positividade é uma violência sistêmica:

Tanto a "violência simbólica" de Bourdieu quanto a "violência estrutural" de Galtung distinguem-se da violência sistémica que atinge indistintamente todos os membros de um sistema social, transformando-os em vítima que, assim, não necessitam de qualquer antagonismo entre as classes, de uma relação hierárquica de cima ou de baixo para seu desenvolvimento. Isso acontece sem a ocorrência de inimizade ou dominação. Seu sujeito sustentador não é uma personalidade que detém o poder, nem uma classe dominante, mas o próprio sistema. (HAN, 2017b, p. 169).

Assim, com a violência sistêmica se manifestando como uma violência da positividade, não existe mais o imperativo da negatividade, do impedimento, da proibição ou da exclusão. A violência da positividade se manifesta no excesso, na exaustão que é produzida em nossa sociedade atual como um todo. Uma sociedade em que a violência é contra o aparelho psíquico de seus integrantes apresentará altos índices de depressão, ansiedade e síndrome de burnout:

Por isso, a violência da positividade é provavelmente muito mais danosa do que a violência da negativa. Os crescentes distúrbios neuronais, como depressão e burnout, são um sinal convincente de recusa e de negação daquilo que impera e domina. Aqui desaparece também a distinção entre explorados e exploradores (...) A vítima é ao mesmo tempo a cúmplice do sistema. (HAN, 2017b, p. 170).

Reiteramos aqui que, não necessariamente, a presença de um novo tipo de violência, baseada na positividade, elimina a existência das formas anteriores. Da mesma maneira, não é porque existe uma violência sistêmica que devemos acreditar que deixaram de existir violências baseadas no caráter exploratório. A violência da negatividade - carregada de exclusões e impedimentos - e a exploração do outro, dito oprimido, ainda são comuns, sobretudo, nas regiões empobrecidas e marginalizadas. Somado a isso, mesmo essas regiões, enfrentaram, nas últimas duas décadas, uma relativa modernização e acesso, ainda que com suas devidas limitações, a um mercado de consumo. Assim, o que se vê nessas periferias urbanas é, ao mesmo tempo, uma violência estrutural e cultural dada em 
decorrência de seu contexto local, e uma violência da positividade dada ao seu contexto histórico.

\section{Propostas de práticas educacionais pertinentes ao tema exposto: convivência, afetividade e uma educação para paz}

E onde a educação se encontra no meio de tudo isso? Numa posição de centralidade, é o que esperamos. Como disse Paulo Freire: "Se a educação sozinha não transforma a sociedade, sem ela tampouco a sociedade muda" (FREIRE, 2000, p. 67). Assim, embora a educação não seja - e nem deva ser - a responsável por resolver todas as mazelas da sociedade, passa, invariavelmente, por ela, qualquer tentativa de transformação social. ${ }^{13}$ Sobre o papel da escola, como lembra Ana Bock et. al.:

A escola apresenta-se, hoje, como uma das mais importantes instituições sociais por fazer, assim como outras, a mediação entre o indivíduo e a sociedade. Ao transmitir a cultura e, com ela, modelos sociais de comportamento e valores morais, a escola permite que a criança "humanize-se", cultive-se, socialize-se ou, numa palavra, eduque-se. A criança, então, vai deixando de imitar os comportamentos adultos para, aos poucos, apropriar-se dos modelos e valores transmitidos pela escola, aumentando, assim, sua autonomia e seu pertencimento ao grupo social. (BOCK et. al., 2001, p. 261).

Na verdade, se há algo a se acrescentar no trecho de Bock é que, não só a escola representa tal papel na sociedade, mas sim, a Educação como um todo - em uma perspectiva ampliada, nas suas esferas formais e não formais. Sobretudo nas regiões mais vulneráveis, é a educação não formal - por meio de projetos sociais, ONGs, etc. - que atua buscando atenuar as faltas causadas pelas desigualdades sociais e, de certa forma, sanar as demandas de sua população empobrecida. Como dito por Geraldo Caliman:

Algumas características básicas dessas atividades e/ou instituições socioeducativas é que elas: são atividades de cuidado e ajuda que se situam tanto no âmbito da assistência social como da educação social. E por isso

\footnotetext{
13 Como bem visto em Paro (2012): "A escola coloca-se como apenas uma das instâncias onde se realiza tal transformação [social]. Pretender que ela se constitua na grande equalizadora social (...) é incorrer no equívoco de imputar, a uma instituição apenas, aquilo que é função da sociedade como um todo. Igualmente equivocada é a atitude de negar à escola qualquer papel na transformação social, esperando que a sociedade mude para mudar a escola. Porque a escola não é o local da mudança, não significa que ele não possa ser um dos locais dessa mudança." (p. 146-147).
} 
são chamadas de atividades ou instituições socioeducativas; que respondem a necessidades específicas de determinados setores da sociedade, particularmente das crianças, adolescentes e jovens; que, em boa parte, se utilizam do trabalho voluntário. (CALIMAN, 2010, p. 344).

Partindo daí, é importante apontar, ainda, que não é qualquer tipo de educação que servirá como meio de combate às violências e às desigualdades sofridas pelas populações marginalizadas. Uma "educação bancária", ${ }_{14}^{14}$ pautada apenas em objetivos tecnicistas que visem à preparação do aluno para o mercado de trabalho, não é uma educação transformadora. É claro que a inserção de um aluno pobre num trabalho que lhe condicione melhores condições financeiras pode fazer com que esse supere alguns de seus problemas materiais, mas ainda Ihe faltariam outras demandas ligadas à cidadania a serem resolvidas. Como destaca Freire (2018, p. 47), ensinar não é apenas transferir conhecimento: ensinar parte da criação de possibilidades para sua própria produção ou construção.

Foi a partir dessa perspectiva que, após os trabalhos de campo no pré-vestibular do Salgueiro, propomos o modelo de Educação para Paz-Cidadania (LOPES, 2019). Dadas às devidas limitações, no entanto, o artigo anterior não dá conta de apresentar todas as características desse modelo, assim como, por muitas vezes, resultou num mal-entendido de que se tratava de uma proposta apenas para as práticas em pré-vestibulares comunitários, ou válida para a localidade do Salgueiro. Tais percepções não estão corretas. A proposta de Educação para Paz-Cidadania não é uma tentativa de "reinventar a roda" das práticas de ensino; o que se faz, nesse caso, é unir algumas referências, que, a princípio, não dialogavam diretamente, e buscar um modelo que tente dar conta das demandas específicas das populações socialmente mais vulneráveis.

No presente artigo, especificamente, tratamos do uso da Educação para PazCidadania no que tange a um de seus objetivos específicos e primários: o uso da educação como forma de combate às violências. Portanto, pontos como as práticas de ensino visando ao desenvolvimento da cidadania dos educandos, que seria uma etapa posterior do processo, ficam em segundo plano aqui - o que não diminui sua importância. É somente com uma

\footnotetext{
${ }^{14}$ Sobre educação bancária: "A educação se torna um ato de depositar, em que os educandos são os depositários e o educador o depositante (...) Na visão 'bancária' da educação, o 'saber' é uma doação dos que se julgam sábios aos que julgam nada saber". (FREIRE, 1987, p. 58).
} 
educação que vise, como fim último, à construção de cidadania, buscando fortalecer os direitos políticos e sociais dos educandos, que alcançaremos um desenvolvimento pleno de sujeitos conscientes e ativos de seus deveres e atuações numa democracia plena. Precedente a isso, no que se refere ao combate das violências através da educação, separamos os três pontos mais relevantes para sua aplicabilidade: a convivência, a afetividade e a Educação para a Paz em si. Vamos desenvolver esses três pontos a seguir.

Para falarmos de convivência na educação, não podemos deixar de trazer para o debate a Pedagogia da Convivência de Xesús Jares. O autor catalão coloca o ato de conviver entre os indivíduos envolvidos no processo educacional na centralidade do processo de ensino-aprendizagem. Desta forma, a Pedagogia da Convivência nos oferece como aporte para o trabalho socioeducativo elementos a serem levados em consideração pelo educador ao elaborar suas práticas didáticas para com as camadas empobrecidas. São elementos essenciais: o respeito; o diálogo; a solidariedade; a não violência; o laicismo; o perdão; a dinâmica de cultura; a ternura; a diversidade e a felicidade (JARES, 2008). Como lembra Ferreira: "os educadores sociais que assumirem a Pedagogia da Convivência como fundamento de sua prática socioeducacional se comprometem com uma postura específica diante do campo de aprendizagem social" (FERREIRA, 2018, p. 42). E que postura é essa? Para Jares, a postura da Pedagogia da Convivência é uma postura que pressupõe os Direitos Humanos como marco regulador. Sendo assim, sua ideia central se dá por "dignidade, inerente a todo ser humano" (JARES, 2008, p. 29).

É de relevância, ainda, "fugir" do significado que o conviver toma, muitas vezes, quando aplicado pelo senso comum; na teoria de Jares (2008), a convivência se refere ao relacionamento, em determinado contexto social, a partir de códigos valorativos, e não simplesmente "estar ao lado". Conviver também implica uma permanente relação de conflito, que pode - e deve - ser geradora de potencialidades a partir da mediação adequada. O conflito, quando mediado adequadamente, a partir de uma lógica de não violência, tem enorme potencial de criação (Muller, 2006). A mediação que se dá nessa relação de conflitos, inerente à convivência humana, deve estar pautada numa Educação para o Desenvolvimento Humano, que, por sua vez, contribuirá à Educação para Paz. O que o autor mostra é que não teremos - e nem devemos desejar ter - uma educação isenta de conflitos. Tal como a 
convivência é o elemento central da educação, o conflito é um aspecto inerente da convivência, portanto, não existe educação ou prática educativa sem conflitos.

Para Jares, enfim, o combate às violências passa diretamente pelo ensino do convívio, tanto para o sistema escolar, quanto para a educação não formal:

Partindo da complexidade de nossas sociedades, seu crescente multiculturalismo, processos de globalização, maior conflituosidade, presença da violência, que envolve todo o tecido social, voltamos de novo nossa atenção tanto para o sistema educacional quanto para a educação não formal, para exigir-lhes o ensino do convívio, a fim de facilitar os processos de convivência social em escalas local e internacional, sensibilizando sobre a necessidade de eliminar toda forma de violência como meio de resolução de conflitos. (JARES, 2007a, p. 157).

A convivência democrática e os Direitos Humanos são um tema chave para o futuro da Educação para Paz (JARES, 2007a, p.18). Sendo assim, pensamos na Pedagogia da Convivência como um conjunto de ações que servem de base para o melhor desenvolvimento de uma Educação para Paz.

Outra questão, em Jares, se faz urgente: a formação do professor. Com professores majoritariamente transmissores de conteúdo, o aluno se torna, cada vez mais, um memorizador, sem desenvolver plenamente sua capacidade crítica; quando, ainda assim, o professor "foge" do perfil mecanicista de ensino, raras vezes esse tem formação adequada em temas de conflito e convivência (JARES, 2007). Como encontrado nos exemplos das aulas em LOPES (2019), diversos temas que serviriam potencialmente a uma Educação para Paz aparecem, mas sem uma mediação adequada do educador, o que se vê é uma mera reprodução das violências. Vejamos um relato da aula de Química, como exemplo:

Aluna A relata: "Antes da eleição o tiro quase acertou minha casa, do exército...". O Professor questiona: "Você tava no baile?". "Não! Tava em casa! Eram 8h!", disse a Aluna A. Aluna B diz: "Eleição não pode prender né?!". Professor: "Se não pode prender então mata!". Aluna B: "Você fala rindo, como se fosse normal...". Professor: "Normal é morrer cedo vé...". As alunas riram e protestaram, uma delas comenta: "Parece psicopata!". Professor responde: "Ah, vocês me veem muito mal!". A aula se inicia depois dessas primeiras conversas, com o Professor passando alguns conteúdos no quadro. Num momento, ele mesmo interrompe a cópia e puxa assunto com uma aluna: "Aí, cê já viu algum baleado?". Aluna C: "Não!". Aluna D: "Já até acostumamos... ouvir uns gritos, ver sangue". Professor responde: "É bom né?! Coração dispara, vem uma emoção vendo tiro, tortura...". (LOPES, 2019, p. 69). 
Tais temáticas aparecerem numa aula de Química é ainda mais notável. O primeiro ponto que podemos tirar é que, invariavelmente, o contexto dos educandos e da comunidade ao redor vai entrar em sala de aula. Ainda que a aula não tenha em seu planejamento inicial nenhum tema que aborde assuntos similares, a vivência dos alunos vai "transbordar" em algum momento. A aparição dos relatos de violência numa classe não é mais uma escolha do docente, a maneira como ele vai lidar com essas violências sim. Apesar da importância que se tem em destacar tais temáticas durante as aulas, como foi o caso desse professor, os trechos acima não representam uma Educação para Paz. A maneira como o Professor abordou os assuntos foi completamente descontextualizada da prática docente e dos temas da aula, tendo, ainda, o agravante de suas falas reproduzirem, ainda mais, uma violência cultural.

Agir com desdém e insensibilidade para com as mazelas dos alunos, nesse caso, se tornou mais agressivo do que seria uma completa apatia do educador frente aos relatos. Quando a Aluna A relata que quase teve sua casa atingida por um tiro do Exército durante a Intervenção Militar, a reação do Professor foi de tentar culpabilizar a vítima: "Você tava no baile?". Como se justificasse a violência direta para uma parcela da população local. Da mesma forma, nas falas seguintes, o que se tem é uma banalização da violência, das mortes, legitimando aquilo que, notadamente, são práticas que violam qualquer tipo de legalidade.

Quanto à relação desse educador com suas alunas, a obra de Jares se faz de extrema relevância ao destacar como um dos princípios de sua Pedagogia da Convivência a "Ternura como paradigma de convivência"; o autor destaca que: "A ternura é uma necessidade vital dos seres humanos e, consequentemente, deve sê-lo também em todo processo educativo" (JARES, 2008, p. 40). E também: "As palavras doces e respeitosas, as mãos sensíveis que sustentam e acariciam, os abraços que transmitem energia, amor, são formas de relação que denotam um modelo de convivência salutar" (JARES, 2018, p.43).

A partir dessas reflexões podemos adicionar ao nosso debate a esfera da afetividade como elemento fundamental nas práticas de ensino que visam à eliminação das violências. $O$ uso das afetividades - na perspectiva de Henri Wallon - nas práticas socioeducativas foi o tema central de outra pesquisa de campo no Complexo do Salgueiro, presente em Ferreira e Lopes (2019). A partir dos resultados dessa pesquisa, foi concluído que o uso de uma afetividade positiva, a partir de práticas que incentivem o aluno ao desenvolvimento de maior autonomia, gera resultados mais eficazes no processo de aprendizagem. 
Para Wallon, a superação das crises da adolescência será mais bem resolvida quanto melhores forem suas condições orgânicas, sociais, culturais, históricas, etc. A partir disso, Abigail Mahoney e Laurinda de Almeida (2005), sistematizando o pensamento do psicólogo francês, apresentam uma forma de pensar a afetividade nos processos educacionais. Segundo as autoras, "[Afetividade] Refere-se à capacidade, à disposição do ser humano de ser afetado pelo mundo externo/interno por sensações ligadas a tonalidades agradáveis ou desagradáveis" (MAHONEY; ALMEIDA, 2005, p. 19). Portanto, ao falarmos de afetividade, devemos levar em conta que essa não é intrinsecamente positiva, como o senso comum aponta. Para Wallon, o afeto (positivo ou negativo), influencia diretamente a aprendizagem. Pensando por esse olhar, é ainda mais essencial a convivência estabelecida entre professoraluno, sendo essa uma relação dialética.

No já citado artigo de Ferreira e Lopes (2019), isso ficou exemplificado com o caso da "Aluna $A$ ", uma menina de 5 anos, no estágio personalista: 15

A garota de cinco anos (no estágio personalista) tenta chamar a atenção para si, característica própria do seu estágio de desenvolvimento predominantemente emocional. Essa garota, ao não receber o retorno esperado - vendo-se ignorada ou alvo de reclamações da turma -, não consegue desenvolver nem mesmo as atividades mais básicas, outrora feitas por ela na aula anterior. Ela é afetada negativamente. Por duas aulas seguidas, ela tenta escrever seu nome numa folha e treinar a escrita das vogais. Na primeira aula dessa oficina, ela conseguiu cumprir isso, na segunda não. (FERREIRA; LOPES, 2019, p. 17).

Como visto nesse exemplo, a aluna não só não conseguiu se desenvolver mais nessa aula em específico, como nem mesmo conseguiu repetir as atividades que já vinha realizando nas aulas anteriores. Na sequência do artigo, ao relatar o "desenrolar" do caso, vê-se que a educadora da oficina notou as dificuldades e o isolamento da aluna, passando a dar-lhe maior atenção: "Na reta final da aula, a Educadora convida-a para sentarem juntas numa poltrona (...) e assistir a alguns vídeos lúdicos, específicos para a iniciação do processo de alfabetização." (FERREIRA; LOPES, 2019, p. 17). Ao passo que a aluna recebe maior atenção,

\footnotetext{
15 "No estágio de personalismo ( $3^{\circ}$ estágio) que vai dos três aos seis anos de idade, temos como prioridade o processo de formação de personalidade. Temos, nessa fase, a volta da predominância afetiva. Sobre esse estágio, diz Wallon (1995, p. 120): 'nessa idade, a criança ainda tem grandes exigências afetivas, tem sede de solicitude e deve ser cercada de uma atmosfera de ternura'. Em nosso relato do quarto dia, em especial no Noema e Variação Eidética, vemos esse aspecto numa garota de cinco anos que faz parte da oficina 'Escola Dinâmica'". (FERREIRA; LOPES, 2019, p. 11).
} 
esse "fracasso" da aluna nas atividades propostas conseguiu ser atenuado, voltando a ter para si um desenvolvimento satisfatório.

Ainda que esse exemplo tenha tratado do caso de uma criança ainda muito nova, isso não significa que a afetividade positiva só seria uma ferramenta efetiva para uma faixa de idade específica. Como se conclui nesse mesmo artigo, no qual foram vistos exemplos de diferentes afetividades para diversas idades, nota-se que:

O maior uso de uma afetividade positiva, de empatia e encorajamento para uma autonomia do aluno, gera resultados muito mais eficazes no processo educativo, em particular, quando respeitado o tempo de desenvolvimento e o contexto social no qual esse aluno está inserido. (FERREIRA; LOPES, 2019, p. 19).

Da mesma forma, tais necessidades afetivas não deixam de interferir em nossos processos de desenvolvimento mesmo quando adultos. É o que nos mostra a Teoria Psicossocial de Erik Erikson, influenciada pela psicanálise freudiana. Segundo Erikson, o desenvolvimento humano se dá durante todo o ciclo vital, tendo, em cada nova etapa do processo evolutivo, novas exigências, necessidades e crises específicas, que afetam a maneira como passamos de um estágio para outro de nossas vidas, tal como se esses serão superados de maneira positiva ou não (BRAGHIROLLI et. al., 1994, p. 106). Como destaca: "Um ser humano é, em qualquer época, um organismo, um ego e um membro da sociedade (...) Seu corpo está exposto a dor e tensão: seu ego, à ansiedade e, como membro de uma sociedade, é suscetível ao pânico que emana de seu corpo" (ERIKSON, 1976a, p. 30 apud BRAGHIROLLI et. al., 1994, p. 105). Como se infere, ao considerar um ser humano que tem necessidades e crises específicas em cada uma de suas idades, sendo essas fortemente influenciadas por seus meios sociais e históricos, tais como por suas interações sociais, uma afetividade positiva e um olhar atento para com as subjetividades dos educandos são sempre elementos essenciais no ato de educar.

Cabe destacar, ainda, o notável cuidado que hoje se faz necessário em relação à violência da positividade. Os ensaios de Byung-Chul Han acerca das novas formas de (auto)dominação dos tempos atuais são verdadeiramente alarmantes para todos que vivem no mundo contemporâneo globalizado:

A sociedade do século 21 não é mais a sociedade disciplinar, mas uma sociedade do desempenho. Também seus habitantes não se chamam mais 'sujeitos da obediência'. São empresários de si mesmos. (...) No lugar de 
proibição, mandamento ou lei, entram projeto, iniciativa e motivação. A sociedade disciplinar ainda está dominada pelo não. Sua negatividade gera loucos e delinquentes. A sociedade do desempenho, ao contrário, produz depressivos e fracassados. (HAN, 2017a, p. 23-25).

É a partir dessa ótica que Han considera que doenças como a depressão, o Transtorno do déficit de atenção com hiperatividade (TDAH), o Transtorno de personalidade limítrofe (TPL) ou a síndrome de burnout são as determinantes da paisagem patológica do começo de nosso século (HAN, 2017a). Nesse sentido, as instituições educacionais - de maneira generalizante -, infelizmente ainda não conseguiram se adaptar a essas novas demandas, e muito pior: por grandes vezes, é uma das maiores reprodutoras de tais violências. Segundo levantamento da Associação Nacional dos Dirigentes das Instituições Federais de Ensino Superior (Andifes) divulgado em 2016, e que contou com a participação de mais de 900 mil graduandos de 62 instituições, com média de idade de 24 anos, sete em cada dez educandos de instituições federais no Brasil vêm sofrendo algum tipo de dificuldade mental ou emocional, como ansiedade, estresse ou depressão. As pesquisais internacionais, tal como, indicam perspectivas bem parecidas. ${ }^{16}$ A psicóloga Leila Tardivo (USP) destaca algumas das causas de tal incidência: "a pressão sofrida pelos jovens, as altas expectativas e a falta de preparo psicológico para a vida acadêmica". ${ }^{17}$ Para além das universidades, o perfil do estudante brasileiro em si, vem se tornando cada vez mais sinônimo de estresse e tensão. De acordo com pesquisa do Programa Internacional de Avaliação de Estudantes (PISA) de 2015, os níveis de ansiedade dos estudantes brasileiros só ficam atrás dos costarriquenhos: $80,8 \%$ se sentem ansiosos durante avaliações e $56 \%$ ficam tensos durante os estudos. ${ }^{18}$

Logicamente tais pesquisas e dados merecem muito maior atenção e análise mais apurada do que podemos oferecer nesse artigo, porém, não poderia passar em branco a relevância de tal assunto ao tratar das violências e de suas possíveis formas de combate. Nesse ponto, um educador que eduque para a paz, não deve ser mais um a cobrar,

\footnotetext{
${ }^{16}$ disponível em: https://desafiosdaeducacao.grupoa.com.br/ansiedade-e-depressao-na-universidade/. Acesso em 05 de janeiro de 2020 .

17 disponível em: https://www.gazetadopovo.com.br/educacao/as-universidades-estao-deprimindo-osestudantes-3wv3zcbxvb6ds2tjze3brm9qg/. Acesso em o5 de janeiro de 2020.

18 disponível em: https://www.gazetadopovo.com.br/educacao/estudantes-brasileiros-estao-entre-os-maisestressados-do-mundo-3bg3ab4zb2q9wn51v3covfzze/?ref=link-interno-materia. Acesso em o5 de janeiro de 2020.
} 
indiscriminadamente, um desempenho sub-humano de seus alunos, a colocar uma meta de superprodução como um padrão normal. Como tanto frisamos aqui, respeitar o tempo do aluno e seu contexto é uma maneira de aumentar a eficácia dos processos de aprendizagem. Por mais que soe contraditório, não é almejando um superdesempenho dos educandos que esse, de fato, será alcançado. Violentar a psique do seu aluno é tão grave como qualquer outra violência. Da mesma forma, se a educação (escolar ou não escolar) é um espaço de construção de valores, cidadania e códigos valorativos, deve caber também a ela, um diálogo necessário com temas contemporâneos tão caros: sobre doenças mentais, suicídio, inteligência emocional, qualidade de vida, auto cobranças, mundo do trabalho, etc.

Mais ainda, ao pensar em alunos em situações socialmente vulneráveis, novas demandas se colocam em pauta em grande medida: educandos que, por muitas vezes, são trabalhadores (e responsáveis pelo sustento de sua casa), que cuidam da maior parte de suas tarefas domésticas, que exercem papel de mãe ou pai, que colocam no sucesso escolar sua única esperança de ascensão... situações que, muitas vezes, o educador ignora e classifica como assuntos que não dizem respeito à escola. A pessoa periférica é, nessa situação, aquela que é explorada pelas classes hegemônicas e pelo Estado, onde se manifestam desigualdades sociais, exclusões, falta de acesso a serviços básicos, preconceitos (de gênero, raça, crença, etc.) e, simultaneamente, por si mesmo, ao se cobrar cada vez mais por produtividade, desempenho e consumo, adoecendo psiquicamente ao tentar alcançar padrões que lhe são inviáveis. O paradigma da ação nas margens, atualmente, é referente ao modo que se combate as violências que atingem o corpo, a cultura, os acessos e a mente do cidadão alvo. Todos pontos essenciais para a prática do educador.

A partir desse elo, da importância da afetividade positiva nas práticas de ensinoaprendizagem, é que também podemos retomar alguns dos elementos principais da Pedagogia da Convivência de Xesús Jares. Ainda que o autor catalão não fale especificamente sobre afetividade, Jares nos mostra que elementos como o respeito, a ternura e a felicidade fazem parte da postura que deve ser tomada pelo educador em suas práticas. O respeito é uma das normas básicas da convivência, levando implícita uma ideia de dignidade humana, já que, sem ele, a convivência democrática se torna impossível. A ternura é uma necessidade vital de todo ser humano, e deve ser considerada nas formas de conviver, visto que o afeto é válido e potencializador às práticas educativas. Além dela, a felicidade, como bem-estar 
material ou imaterial, é um conteúdo que precisa ser desenvolvida no processo de convivência com o outro: mostrando que é possível ser feliz, carregando um desejo de encantamento pela vida, gerando esperança de transformação social.

Com base nesses dois elementos - a convivência e a afetividade -, agora sim, podemos falar mais especificamente da Educação para Paz em si, chegando a linhas mais conclusivas desse artigo. É nesse sentido onde buscamos um projeto educacional para paz, de não naturalização de situações de violências, buscando, pela educação, a consciência de sua existência e, assim, objetivando sua eliminação: eliminação de desigualdades, repressões e ataques contra os direitos humanos.

Concebemos a EP [Educação para Paz] como processo educativo, contínuo e permanente (...) que, pela aplicação de métodos problematizantes, pretende desenvolver um novo tipo de cultura, a cultura da paz, que ajude as pessoas a entender criticamente a realidade, desigual, violenta, complexa e conflituosa, para poder ter uma atitude e uma ação diante dela. (JARES, 2007, p. 44-45).

Ao pensarmos em Educação para Paz, então, devemos levar em conta dois conceitos fundamentais: paz positiva e conflito (a partir de sua perspectiva criativa). Para Jares, a paz positiva se diferencia da visão tradicional de paz, como ausência de guerras, ou conflitos em geral. A paz positiva não é antítese de guerra, mas sim, antítese da violência, em todas as suas esferas. Sendo assim, como podemos concluir: "chamar uma situação onde imperam a pobreza, a repressão e a alienação de paz, é um arremedo do conceito de paz". (GALTUNG apud JARES, 2007, p. 33). Da mesma maneira, como dito anteriormente, o conflito é visto como natural e necessário à condição humana. (JARES, 2002, p. 134).

Podemos aplicar esses dois conceitos a partir de exemplos vistos nas pesquisas realizadas anteriormente. Sobre a amplitude do conceito de paz positiva, a já citada aula de Química do pré-vestibular nos fornece outro caso para análise:

O assunto entra em temas como filmes, novelas... uma aluna diz: "Ah... novela da Globo sem mensagem nenhuma... homem com homem, mulher com mulher". Professor responde: "Esses caras que gostam de curtição agora querem pegar homem". Aluna: "E ainda tem esses negócios de Bi...". Outra aluna: "E homem que se veste de mulher". O Professor faz algumas brincadeiras sobre um "travesti" que viu na rua. As alunas, no geral, riem bastante durante essa parte da conversa, contam mais alguns relatos de conhecidos que ficaram com "travestis". Por fim, o tempo da aula se encerra. (LOPES, 2019, p. 70). 
Novamente temas dialógicos com a violência aparecem, mas, agora, em um caráter mais geral. O discurso preconceituoso é visto como brincadeira, nesse caso, onde contavam relatos sobre pessoas transgênero, escarnecendo-as. É também criticada a Rede Globo que supostamente incentivaria "comportamentos gays" em seus programas. Nesse caso, são as alunas que apresentam esse tema, e o professor acaba incentivando que ele se mantenha, colaborando e legitimando uma visão violenta acerca das questões de gênero. Nesse caso, se o assunto fosse realmente inevitável e relevante em sala - o que se mostra pouco provável na ocasião -, o educador poderia aproveitar o interesse das alunas em tratar desses assuntos para desnaturalizar tais visões preconceituosas e hostis acerca de tais parcelas da população, trazendo uma visão mais embasada e não violenta.

Quanto ao conflito, podemos retomar um exemplo encontrado em Ferreira e Lopes (2019), visto numa oficina de reciclagem na ONG Luxo de Vida:

O garoto da turma pede ajuda por não saber fazer determinado recorte sozinho. A Educadora se põe a fazer para ele. Quase todo o resto da turma se coloca em protesto, repetindo que se fosse assim, ela deveria fazer para todos os outros alunos. Pouco depois do fato, esse aluno se levanta e vai para a parte externa da sede. (...)

O Aluno B já não demonstrava uma grande motivação em seu início de trabalho. Logo após ele se tornar alvo dos colegas de oficina, sua reação instintiva é sair daquele lugar, desistir completamente da atividade. (FERREIRA; LOPES, 2019, p. 17)

No exemplo citado acima, o conflito passa pela falta de diálogo da educadora com os alunos, que não permitem que ela faça a atividade de apenas um dos educandos, já que, como dito por ela, todos deveriam realizar o mesmo trabalho. Diante disso, a educadora poderia ter utilizado a situação de conflito para incentivar uma prática de solidariedade entre os alunos, ou seja, ponderar que seria permitido ajudar o colega que não conseguisse realizar a atividade, evitando, assim, a desistência da atividade do aluno que havia pedido ajuda.

Por fim, se podemos resumir a ligação dos três conceitos apresentados nesse tópico em um parágrafo, podemos começar assim: toda prática educativa parte de uma relação social, essa, baseada num modelo específico de convivência - que, aqui, amparados em Jares, definimos como democrática e pautada nos Direitos Humanos - existente entre educando, educador e meio; se, então, o ato de educar pressupõe o ato de conviver, toda relação estabelecida afeta, de alguma forma, o outro com o qual estabelecemos contato, podendo essa afetividade ser positiva ou negativa. Somente ao partirmos de uma convivência 
comprometida com uma afetividade positiva, de respeito ao nosso educando e sua cultura, de ternura e felicidade, podemos "nos legitimar" a atuar numa Educação para Paz, numa prática de ensino (em suas metodologias, avaliações, conteúdos, objetivos, linguagem, etc.) que se oponha às violências e desigualdades sociais.

Nessas bases se estabelece, portanto, a Educação para Paz-Cidadania, modelo que "pressupõe um professor/educador social preparado para lidar com temas de convivência, tal como (...) comprometido com uma prática educadora para a paz (...) e em busca da autonomia de seus educandos" (LOPES, 2019, p. 97), visando, por fim último, à Educação como ferramenta de formação de cidadania ${ }^{19}$ para a sociedade.

\section{Considerações finais}

Ao chegarmos a algumas conclusões do que foi organizado até o presente momento, podemos entender que a convivência e a afetividade são essenciais na construção de práticas socioeducativas, tão fundamentais para espaços de violências. Dessa forma, emerge a figura do terceiro setor presente nos espaços de vulnerabilidade onde o Estado não atua de maneira efetiva para atender às demandas da população. Nos espaços formais, verifica-se a falta de uma oferta de educação de qualidade, cursos profissionalizantes, atividades de cultura e lazer... é um fato: onde existe uma comunidade empobrecida nem sempre há uma comunidade educativa. Dessa forma, é a sociedade civil quem organiza formas de resistência, inclusive, para o problema das violências, em que as políticas públicas não mostraram resultados satisfatórios. Nesse sentido - de combater as violências -, nota-se que as práticas socioeducativas que utilizam recursos como a convivência e a afetividade, apresentam

\footnotetext{
19 Nesse ponto, devemos perguntar, o que é educar para a cidadania? Em meio a tantos debates acerca desse termo tão controverso, ficamos com a definição de Moacir Gadotti, apoiado em Paulo Freire: "O que é educar para a cidadania? A resposta dessa pergunta depende da resposta à outra pergunta: o que é cidadania? Pode-se dizer que cidadania é essencialmente consciência de direitos e deveres e exercício da democracia: direitos civis, como segurança e locomoção; direitos sociais, como trabalho, salário justo, saúde, educação, habitação, etc. direitos políticos, como liberdade de expressão, de voto, de participação em partidos políticos e sindicatos, etc. Não há cidadania sem democracia (...) O que é educação para e pela cidadania? Parece que foi Paulo Freire quem melhor definiu uma educação para e pela cidadania (...): A Escola Cidadã é aquela que se assume como um centro de direitos e deveres. O que a caracteriza é a formação para cidadania. A Escola Cidadã, então, é a escola que viabiliza a cidadania de quem está nela e de quem vem a ela (...). É uma escola de produção comum do saber e da liberdade. É uma escola que vive a experiência tensa da democracia. (GADOTTI, 2012, p. 1-2, grifos do original)".
} 
resultados mais satisfatórios nos processos de ensino-aprendizagem, chegando, dessa maneira, mais próximos de alcançar nossa proposta de um modelo de Educação para PazCidadania.

$\mathrm{E}$, o que ocorre quando a instituição educacional se fecha ao que está ao seu redor, à realidade do educando fora daquele espaço? Tal fato gera, constantemente, o que Pierre Bourdieu chama de o "mal-estar nas escolas" (BOURDIEU; CHAMPAGNE, 2001), em que, mesmo quando os alunos mais pobres conseguem adentrar à escola, parecem cada vez mais distantes dali. A escola que o "aceita", não aceita sua cultura. Assim, é cada vez mais comum ver alunos desistindo dos estudos para dedicar todo seu tempo trabalhando, ajudando em casa; ele não se sente confortável na escola, que passa a ser um engodo para ele e sua família. Assim, esperamos, ainda, que tal artigo nos dê a possibilidade de refletir quanto ao acesso no sentido mais amplo possível - dos alunos à educação. A Escola/Instituição que visa ser democrática deve se adaptar culturalmente aos alunos e não tentar deformar o que ele traz de experiência consigo. Enquanto a escola segregar culturalmente, as expressões que os alunos trarão a ela serão simplesmente para lembrar à escola que "a vida verdadeira está fora dai" (BOURDIEU; CHAMPAGNE, 2001, p. 486).

O contexto deve vir antes da prática em si. O social e o histórico devem vir antes de qualquer modelo pedagógico. Afinal, uma educação que vise à humanização, pautada num código universal como os Direitos Humanos e os valores democráticos, deve sempre partir das demandas específicas e da realidade sociocultural em que está inserido seu ambiente educativo. A instituição educativa só pode se fazer bem-sucedida na missão de transformar vidas, quando essas vidas são conhecidas, quando há diálogo, convivência. Nesse artigo, o Complexo do Salgueiro é apenas um plano de fundo para destacar a importância do contexto na formulação de práticas educativas transformadoras. A proposta de Educação para PazCidadania tem, em sua essência mais única, o dever primário de conhecer as subjetividades, não só da instituição educacional à qual será aplicada, mas as de seus educandos e da comunidade em que estão inseridos, fazendo valer a máxima de que toda Pedagogia é uma Pedagogia social. 


\section{Referências}

BOCK, A. M. B.; FURTADO, O.; TEIXEIRA, M. de L. T. Psicologias - Uma introdução ao estudo da Psicologia. São Paulo: Editora Saraiva, 2001.

BOURDIEU, P.; CHAMPAGNE, P. Os excluídos do interior. In: BOURDIEU, Pierre. A Miséria do Mundo. Petrópolis: Editora Vozes, 2001.

BRAGHIROLLI, E. M.; PEREIRA, S.; RIZZON, L. A. Temas de Psicologia Social. Petrópolis, RJ: Vozes, 1994.

CALIMAN, G. Pedagogia Social: seu potencial crítico e transformador. Revista de Ciências da Educação, Americana, n. 23, p. 341-368, 2010.

COSTA, G. V. L. da. Das Fronteiras Nacionais às Fronteiras Internas: Segurança, Ordem e Tutela Militar no Brasil. Revista TOMO, São Cristóvão, Sergipe, Brasil, n. 35, p. 7-46, jul./dez. 2019.

DECRETO N 45.186, de 17 DE MARÇO de 2015. Disponível em:

http://www.silep.planejamento.rj.gov.br/decreto_45_186_-_17032015_-_re.htm. Acesso em 18 de dezembro de 2019.

DEPRAZ, N. Compreender Husserl. Petrópolis: Vozes, 2011.

DESAFIOS DA EDUCAÇÃO. Disponível em: https://desafiosdaeducacao.grupoa.com.br/. Acesso em 03 de janeiro de 2020.

FERNANDES JUNIOR, G. L. A metropolização da criminalidade com a territorialização das UPPs: da migração a expansão. Rev. Tamoios, São Gonçalo (RJ), ano 12, n. 1, págs. 20-42, jan/jun, 2016.

FERREIRA, A. V. Pedagogia social e docência ampliada no processo de formação inicial. In: FERREIRA, A. V (org.). Dentro ou fora da sala de aula? O lugar da Pedagogia Social. Curitiba: CRV, 2018.

FERREIRA, A. V.; SILVA, J. V. de A. Onde tem uma comunidade pobre nem sempre tem uma comunidade educativa. A pedagogia social e os espaços educativos em São Gonçalo. IX Seminário Internacional Redes Educativas e Tecnologias. Rio de Janeiro. 2017.

FERREIRA, A. V.; LOPES, L. S. O uso das afetividades em Wallon e as práticas socioeducativas de um projeto social em São Gonçalo-RJ. Revista Debates em Educação, Maceió, Vol. 11, no. 25, set./dez., 2019, p. 1-21.

FREIRE, P. Pedagogia da Autonomia: saberes necessários à prática educativa. Rio de Janeiro/São Paulo: Paz e Terra, 2018.

FREIRE, P. Pedagogia da indignação: cartas pedagógicas e outros escritos. São Paulo: Editora UNESP, 2000.

FREIRE, P. Pedagogia do Oprimido. 17. ed. Rio de Janeiro, Paz e Terra, 1987.

G1 - Portal de Notícias da Globo. Disponível em: https://g1.globo.com/. Acesso em 26 de dezembro de 2019. 
GADOTTI, M. Escola Cidadã: Educação para e pela Cidadania. Acervo do Centro de Referência Paulo Freire, São Paulo, p. 1-12, 2012.

GALTUNG, J. Violence, Peace and Peace Research. Journal of Peace Research, Noruega, vol. 6, n. 3, p. 167-191, 1969 .

GALTUNG, J. La violencia: cultural, estructural y directa. Cuadernos de estratégia. Espanha, n. 183, p. 147-168, 2016.

GAZETA DO POVO. Disponível em: https://www.gazetadopovo.com.br/. Acesso em o3 de janeiro de 2020.

HAN, B. Sociedade do Cansaço. 2. ed. Petrópolis, RJ: Vozes, $2017 a$.

HAN, B. Topologia da Violência. Petrópolis, RJ: Vozes, 2017b.

ISP Visualização - Instituto de Segurança Pública. Disponível em:

http://www.ispvisualizacao.rj.gov.br/. Acesso em 18 de dezembro de 2019.

JARES, X. R. Educação para a Paz: sua teoria e prática. Porto Alegre: Artmed, 2002.

JARES, X. R. Educar para a paz em tempos difíceis. São Paulo: Palas Athena, 2007.

JARES, X. R. Pedagogia da Convivência. São Paulo: Palas Athena, 2008.

LOPES, L. S. EDUCAÇÃO PARA PAZ-CIDADANIA: as (possíveis) práticas socioeducativas num prévestibular comunitário no Complexo do Salgueiro em São Gonçalo-RJ. In: FERREIRA, Arthur Vianna; LOPES, Lucas Salgueiro; DIAS, Thiago Simão (Org.). Fora da Sala de Aula: Formação Docente e Pesquisas sobre Pobreza e Educação. 1. ed. Rio de Janeiro: Autografia, 2019, p. 54-81.

LOPES, L. S.; FERREIRA, A. V. A fenomenologia como possibilidade de método investigativo em pesquisas educacionais. MOVIMENTO - Revista de Educação. Niterói: ano 6, no 10, p. 219-238, jan./jun., 2019.

MAHONEY, A. A.; ALMEIDA; L. R. de. Afetividade e processo ensino-aprendizagem: contribuições de Henri Wallon. Psicologia da Educação, São Paulo, 20, p. 11-30, 2015.

MORAES, J. M. B. Espaço do trabalho e mudanças socioespaciais: a reconstrução dos espaços urbano-fabris no município de São Gonçalo, Estado do Rio de Janeiro. Meridiano - Revista de Geografia, v. 03, p. 67-82, Buenos Aires, Argentina, 2014.

MULLER, J. M. Não violência na educação. São Paulo: Pala Athena, 2006.

OLIVEIRA, J. P. de. Pacificação e Tutela Militar na Gestão de Populações e Territórios. Mana, Vol. 20, no 1, pp. 125-161, 2014.

PARO, V. H. Transformação Social e Educação Escolar. In: PARO, Vitor Henrique. Administração Escolar: introdução crítica. - 17. ed. ver. e ampl. - São Paulo: Cortez, 2012.

PESCAROLO, J. K. Sociologia Urbana e da Violência. Curitiba: Intersaberes, 2017. 
INSTITUTO BRASILEIRO DE GEOGRAFIA E ESTATÍSTICA. São Gonçalo Panorama. Disponível em: https://cidades.ibge.gov.br/brasil/rj/sao-goncalo/panorama. Acesso em 27 de junho de 2019.

TAUFER, L. Atravessando Fronteiras: da guerrilha urbana na Alemanha ao trabalho comunitário em favelas no Brasil. São Paulo: Autonomia Literária, 2018.

\section{Detalhes dos autores}

\section{Arthur Vianna Ferreira}

Doutor em Educação: Psicologia da Educação pela Pontifícia Universidade Católica de São Paulo (PUC-SP). Professor adjunto do Departamento de Educação da Faculdade de Formação de Professores da (UERJ/FFP). Pesquisador associado da Fundação Carlos Chagas (FCC-SP). Coordenador-Pesquisador do Grupo de Estudos, Pesquisas e Extensão Fora da Sala de Aula (UERJ/FFP). Coordenador do Projeto de Extensão TEAR - UERJ/FFP. Coordenador do Projeto Proatec/UERJ, intitulado "Dar formação à ação: Produção de Materiais Didáticos para/com Educadores Sociais em São Gonçalo e Regiões Adjacentes" (UERJ/FFP).

Lucas Salgueiro Lopes

Mestrando em Educação - Processos formativos e Desigualdades Sociais pela Universidade do Estado do Rio de Janeiro (UERJ/FFP). Pós-graduando (lato sensu) em Educação Básica - Gestão Escolar pela UERJ/FFP. Possui Licenciatura Plena em História pela Universidade do Estado do Rio de Janeiro, onde foi monitor das disciplinas de Psicologia da Educação e Psicologia Social durante a graduação, e em Sociologia pelo Centro Universitário Internacional (UNINTER). Membro do Grupo de Estudos, Ensino e Extensão Fora da Sala de Aula da UERJ/FFP. Bolsista CAPES. 